\title{
Diagnóstico etiológico de pacientes con exantemas o cuadros febriles atendidos en 1998. Estado Zulia, Venezuela
}

\author{
Luciana Costa de León ${ }^{1 a}$, Jesús Estévez² \\ Francisca Monsalve de Castillo ${ }^{1 b}$, Diana Callejas ${ }^{1 b}$, \\ José Manuel Echevarría ${ }^{3}$
}

\section{Laboratory diagnosis of patients with exanthematic or febrile syndromes occurring in the Zulia state, Venezuela, during 1998}

Background: Exanthematic diseases are a group of syndromes mainly caused by acute viral infections. Aim: To obtain information about the viruses that cause exanthematic diseases in our region. Patients and methods: During 1998, 267 serum samples from patients with an acute rash or patients presenting a febrile syndrome accompanied by enlarged lymph nodes, headache and other symptoms, were collected. Specific antibody of the IgM class (anti-IgM) against Rubella, Measles, Dengue types 1-4 and Cytomegalovirus (CMV) were measured by immunoenzymatic assay (EIA). Epstein-Barr virus (EBV) antibodies were measured by immunofluorescence. Results: An etiologic agent was detected in 208 cases (77.9\%). Cases due to Dengue (40,6\%) and Rubella (21\%) viruses predominated, but the frequency of other agents was also high in specific age groups. The agreement between the clinical suspicion and the laboratory findings varied broadly, from a $100 \%$ for suspected Dengue to just a $14,8 \%$ for cases of suspected CMV infection. Conclusions: Dengue was the most common viral exanthematic disease in the Zulia State during 1998 (Rev Méd Chile 2004; 132: 1078-84).

(Key Words: Dengue hemorrhagic fever; Exanthema; Rubella)

Recibido el 16 de diciembre, 2003. Aceptado en versión corregida el 15 de julio, 2004.

${ }^{1}$ Escuela de Bioanálisis, Facultad de Medicina. ${ }^{2}$ Sección de Virología, Instituto de Investigaciones Clínicas, Universidad del Zulia, Maracaibo, Venezuela. ${ }^{3}$ Instituto Carlos III, Mahadahonda, Madrid, España.

aMgSc en Ciencias Ambientales

bMgSc en Inmunología Básica

Correspondencia a: Luciana Costa de León. Calle 67a Av. 14a , Edificio Orosi, 4ํ Piso, Apartamento 4B, Maracaibo, Estado Zulia, Venezuela. Telef-Fax: 58-261-7970045.

E-mail: lucianacosta@hispavista.com 
L as enfermedades exantemáticas agudas constituyen un conjunto de síndromes infecciosos que son característicos de la edad infantil y responden, en su mayor proporción, a infecciones víricas. Al margen del exantema vesicular que caracteriza a la varicela, los restantes casos se manifiestan como exantemas maculopapulosos de distribución corporal variable y, en ocasiones, caractenística. Los virus de la rubéola y el sarampión, el Parvovirus Humano B19 (PVB19) y el Herpesvirus Humano 6 (HVH6) son los agentes etiológicos de los exantemas infantiles más comunes en el mundo. En algunos pacientes, su curso clínico es benigno y autolimitado. Sin embargo, algunos casos pueden evolucionar hacia infecciones generalizadas con compromiso de órganos internos (neumonía, encefalitis, hepatitis) y, eventualmente, muerte del paciente. Estas complicaciones son más frecuentes en el sarampión, especialmente cuando sucede en pacientes adultos 0 en lactantes, siendo aún, en algunos países en vías de desarrollo, el sarampión una causa importante de muerte infantil. En pacientes con déficit en la respuesta inmune celular y en niños mal nutridos, las complicaciones suelen ser frecuentes y graves ${ }^{1}$.

Aun cuando el exantema es el síntoma típico de estas infecciones, no es raro observar casos en los que dicha manifestación es inapreciable o falta por completo, como se ha documentado ampliamente en el caso de la rubéola ${ }^{2}$. Cuando esto sucede, la enfermedad cursa como un cuadro febril agudo que suele acompañarse de adenopatías, fiebre y otros síntomas inespecíficos. Con frecuencia, estos casos recuerdan a la mononucleosis infecciosa y son emóneamente diagnosticados como tal. Por otro lado, los principales agentes responsables de este último síndrome virus de Epstein-Barr (VEB) y citomegalovirus (CMV) originan, en no pocas ocasiones, la aparición de un exantema que acompaña a los síntomas de esa enfermedad, lo que también puede dar lugar a emores en el diagnóstico clínico ${ }^{3}$.

Todos los virus mencionados hasta aquí son agentes infecciosos ubicuos, autóctonos de todas las áreas geográficas del globo. Sin embargo, en regiones tropicales existen agentes víricos transmitidos por artrópodos que son exclusivos de ellas y que, con cierta frecuencia, producen exantemas en los pacientes a los que infectan. Tanto por su importancia sanitaria como por su amplia distribución en los trópicos, los virus de la fiebre de dengue (virus dengue, tipos 1-4) son los más importantes ${ }^{4,5}$.
En consecuencia, el estudio de los exantemas víricos agudos en el laboratorio debe contemplar todas esas alternativas para poder ofrecer una panorámica real de la etiología de estas infecciones en una región dada. En primer lugar, habrá de contemplarse el estudio de los cuadros febriles agudos que, por su sintomatología acompañante, puedan ser reflejo de infecciones por virus exantemáticos que cursen sin manifestaciones eruptivas. En segundo lugar, se deberá incluir pruebas capaces de diagnosticar infecciones por otros virus que, no incluyendo el exantema entre los síntomas típicos de la infección, sí puedan inducirlo en algunos casos. En las regiones tropicales, los virus dengue deben ser considerados siempre.

Con el objeto de mejorar el conocimiento de las patologías agudas producidas en nuestro medio por los principales agentes víricos antes mencionados, se han realizado pruebas de laboratorio para diagnóstico etiológico en muestras de suero tomadas de pacientes con enfermedad exantemática aguda y de otros que presentaban síndromes febriles acompañados de otros síntomas seleccionados. El ámbito del estudio fue la ciudad de Maracaibo, en el año 1998.

\section{PACIENTES Y MÉTODOS}

Población. Durante el período comprendido entre enero y diciembre de 1998, se recogieron muestras únicas de suero de 267 pacientes, de edades comprendidas entre 5 meses y 80 años, que presentaban un exantema máculo-papular o un cuadro febril acompañado de dos o más de los siguientes síntomas: adenopatías, cefalea, artralgias y mialgias. En todos los pacientes se registraron, además, datos sobre presencia o ausencia de faringitis, prurito, ictericia, náuseas y vómitos en coincidencia con la enfermedad. Sobre la base de estos síntomas, todos los casos estudiados recibieron un diagnóstico clínico de presunción, en algunos casos más de un diagnóstico, en cuanto al agente responsable del síndrome. Todos los pacientes fueron referidos de diferentes organismos dispensadores de atención en salud del Estado Zulia, Venezuela. A cada uno de estos individuos se les extrajo 5 cc de sangre sin anticoagulante preservando los sueros a $-20^{\circ} \mathrm{C}$ hasta su procesamiento. 
Método. Métodos serológicos: En todos los casos, se investigó la presencia de anticuerpos específicos de la clase IgM frente al virus de la rubéola, virus del sarampión, virus dengue 1-4, CMV y VEB. Se utilizaron métodos comerciales de enzimoinmunoanálisis (EIA) de captura de cadenas pesadas para rubéola (Rubenostika, Organon Teknika, Boxtel, Holanda), sarampión (Virgo Schiaparelli, Columbia, EE.UU) y CMV (Vironostika, Organon Teknika Boxtel, Holanda) cuya capacidad diagnóstica ha sido ya evaluada. Para los virus dengue, se siguió el protocolo de EIA de captura de cadenas pesadas del Centro de Control de Enfermedades (CDC) de Puerto Rico ${ }^{5}$. En el caso del VEB, se investigó la presencia de IgM específica frente al antígeno de la cápside (EBV-VCA) mediante inmunofluorescencia indirecta (Gull Laboratories, Salt Lake City, EE.UU). De acuerdo con los criterios de interpretación establecidos para cada método, se consideró a un resultado positivo diagnóstico de infección aguda reciente por el correspondiente virus. Se excluyeron de este estudio las infecciones por Parvovirus B19 (PVB19) y Herpes Virus Humano 6 (HVH6) en función de que sus sistemas diagnósticos están en una etapa inicial de desarrollo y los mismos son sumamente onerosos.

Estadística. Los datos obtenidos se analizaron mediante la prueba de chi cuadrado, aplicando la corrección de Yates y la prueba exacta de Fisher allí donde fuese oportuno, tomando como significativo cualquier valor de $p<0,05$. Se evaluaron también

\section{Tabla 1. Porcentajes de incidencia de agentes en 267 casos de enfermedad exantémica}

\begin{tabular}{|lrr|}
\hline Patología & \multicolumn{2}{c|}{ IgM positivos } \\
Exantémica & $\mathrm{n}$ & $\%$ \\
& & \\
\hline Rubéola & 56 & 21,0 \\
Dengue & 108 & 40,6 \\
CMV & 4 & 1,5 \\
EBV & 40 & 15,0 \\
No clasificado & 59 & 22,0 \\
Total & $208^{*}$ & 77,9 \\
\hline
\end{tabular}

*Un grupo de 59 pacientes no fue positivo para ninguno de los agentes infecciosos analizados. Total de población estudiada: 267 individuos. gráficos y tablas de distribución de frecuencia para cada una de las variables estudiadas.

Consideraciones éticas. El presente estudio fue aprobado para su realización por el Comité de Ética de la Facultad de Medicina de la Universidad del Zulia. A todos los pacientes o sus representantes les fue solicitado un consentimiento previo por escrito para su inclusión en el estudio, siguiendo los lineamientos de la Declaración de Helsinki para estudios en humanos.

\section{RESULTADOS}

La Tabla 1 muestra el número de casos positivos para cada agente y su participación porcentual sobre el total de casos estudiados. El virus dengue fue el agente más frecuentemente diagnosticado $(40,6 \%)$, seguido por el virus de la rubéola $(21,0 \%)$ y el VEB (15,0\%), siendo muy poco frecuente el diagnóstico de infección por CMV (1,5\%). Ninguno de los casos estudiados reflejó una infección por el virus del sarampión. En 59 (22,0\%) casos, todas las pruebas realizadas resultaron negativas, por lo cual se colocaron en un renglón como no clasificadas».

Cuando se analizaron los resultados positivos en función de la edad de los pacientes (Tabla 2), las infecciones por virus dengue predominaron en todos los grupos de edad, siendo los menores de 10 años los más afectados, seguido por el VEB el cual presentó una prevalencia de 36,4\%. A partir de la edad de 10 años el virus de la rubéola fue, después del virus dengue, el más frecuentemente diagnosticado (29,2\%-35,7\%), si bien continuaron encontrándose infecciones por el EBV (7,2\%9,6\%). Las escasas infecciones por CMV se repartieron más o menos por igual en todos los grupos.

La frecuencia de presentación de los diferentes síntomas en los pacientes con resultados positivos para cada uno de los agentes estudiados se presenta en la Tabla 3. A excepción de los casos de rubéola, en los que el exantema existió siempre, la ausencia de erupción cutánea fue un hecho frecuente en estos pacientes, faltando en casi la mitad de los casos de dengue y de los de infección por VEB. Al margen de éste, los síntomas más frecuentes en esos 267 pacientes fueron: fiebre $(64,2-100 \%)$; cefalea $(55,0 \%-100 \%)$; adenopatías $(41,7-87,5 \%)$; artralgias $(25,0 \%-69,6 \%) ; y$ 
Tabla 2. Prevalencia de agentes según la edad en 267 pacientes con enfermedad exantémica

\begin{tabular}{|c|c|c|c|c|c|c|c|c|c|c|c|c|}
\hline \multirow{3}{*}{$\begin{array}{l}\text { Grupo } \\
\text { de edad } \\
\text { (años) }\end{array}$} & \multicolumn{12}{|c|}{ Patología exantémica } \\
\hline & \multicolumn{2}{|c|}{ Rubéola } & \multicolumn{2}{|c|}{ Dengue } & \multicolumn{2}{|c|}{$\mathrm{CMV}$} & \multicolumn{2}{|c|}{ EBV } & \multicolumn{2}{|c|}{ No clasificados } & \multicolumn{2}{|c|}{ Total } \\
\hline & $\mathrm{n}$ & $\%$ & $\mathrm{n}$ & $\%$ & $\mathrm{n}$ & $\%$ & $\mathrm{n}$ & $\%$ & $\mathrm{n}$ & $\%$ & $\mathrm{n}$ & $\%$ \\
\hline$<1$ & 0 & 0 & 5 & 71,4 & 0 & 0 & 2 & 28,6 & 0 & 0 & 7 & 2,6 \\
\hline $1-10$ & 4 & 6,1 & 34 & 51,5 & 1 & 1,5 & 24 & 36,4 & 3 & 4,5 & 66 & 24,7 \\
\hline $11-20$ & 21 & 29,2 & 31 & 43,1 & 0 & 0 & 6 & 8,3 & 14 & 19,4 & 72 & 26,9 \\
\hline $21-30$ & 18 & 34,6 & 15 & 28,9 & 2 & 3,8 & 5 & 9,6 & 12 & 23,1 & 52 & 19,5 \\
\hline $31-40$ & 10 & 35,7 & 8 & 28,67 & 1 & 3,6 & 2 & 7,2 & 7 & 25,00 & 28 & 10,5 \\
\hline $41-50$ & 3 & 16,7 & 8 & 44,4 & 0 & 0 & 0 & 0 & 7 & 38,9 & 18 & 6,7 \\
\hline$>50$ & 0 & 0 & 7 & 29,2 & 0 & 0 & 1 & 4,2 & 16 & 66,7 & 24 & 8,9 \\
\hline Total & 56 & & 108 & & 4 & & 40 & & 59 & & 267 & \\
\hline
\end{tabular}

Tabla 3. Sintomatología observada en 267 pacientes con enfermedad exantémica

\begin{tabular}{|c|c|c|c|c|c|c|c|c|c|c|}
\hline \multirow{2}{*}{ Síntomas } & \multicolumn{2}{|c|}{ Rubéola } & \multicolumn{4}{|c|}{$\begin{array}{cc} & \text { Patología exantémic } \\
\text { Dengue } & \mathrm{CMV}\end{array}$} & \multicolumn{2}{|c|}{ EBV } & \multicolumn{2}{|c|}{ No clasificados } \\
\hline & $\mathrm{n}$ & $\%$ & $\mathrm{n}$ & $\%$ & $\mathrm{n}$ & $\%$ & $\mathrm{n}$ & $\%$ & $\mathrm{n}$ & $\%$ \\
\hline Fiebre & 36 & 64,2 & 90 & 83,3 & 4 & 100,0 & 36 & 90,0 & 52 & 88,1 \\
\hline Cefalea & 38 & 67,9 & 62 & 57,4 & 4 & 100,0 & 22 & 55,0 & 37 & 62,7 \\
\hline Mialgias & 33 & 58,9 & 35 & 32,4 & 1 & 25,0 & 17 & 42,5 & 31 & 52,5 \\
\hline Artrialgias & 39 & 69,6 & 47 & 43,5 & 1 & 25,0 & 19 & 47,5 & 32 & 54,2 \\
\hline Eritema & 56 & 100,0 & 61 & 56,5 & 1 & 25,0 & 21 & 52,5 & 30 & 50,9 \\
\hline Adenopatía & 49 & 87,5 & 45 & 41,7 & 0 & 0 & 30 & 75,0 & 27 & 45,8 \\
\hline Faringitis & 2 & 3,6 & 7 & 6,5 & 0 & 0 & 2 & 5,0 & 1 & 1,7 \\
\hline Prurito & 7 & 12,5 & 2 & 1,9 & 0 & 0 & 1 & 2,5 & 2 & 3,4 \\
\hline Ictericia & 1 & 1,8 & 24 & 22,2 & 1 & 25,0 & 15 & 37,5 & 13 & 22,0 \\
\hline Náuseas & 0 & 0 & 4 & 3,7 & 2 & 50,0 & 2 & 5,0 & 2 & 3,4 \\
\hline Vómitos & 1 & 1,8 & 34 & 27,8 & 2 & 50,0 & 9 & 22,5 & 17 & 28,8 \\
\hline
\end{tabular}

mialgias (25,0\%-58,9\%). Además, la ictericia y los vómitos fueron moderadamente frecuentes en las infecciones por virus dengue $(22,2 \%$ y $27,8 \%)$ y por VEB (37,5\% y 22,5\%), en tanto que el prurito, la faringitis y las náuseas no fueron frecuentes.

El diagnóstico clínico de presunción realizado en 208 casos $(77,9 \%$ del total) coincidió con el obtenido en el laboratorio en el $71,2 \%$ de los casos diagnosticados clínicamente como rubéola (52/73), el $62,4 \%$ de los casos enjuiciados como dengue $(63 / 101)$, el $50,0 \%$ de los sospechosos de infección por VEB (35/70) y tan sólo el 12,9\% de los que se etiquetaron como infecciones por CMV (4/31 (Tabla 4).
Tabla 4. Valor predictivo del diagnóstico clínico en relación al diagnóstico de laboratorio

\begin{tabular}{|lccc|}
\hline $\begin{array}{l}\text { Patología } \\
\text { exantemática }\end{array}$ & $\begin{array}{c}\text { Diagnóstico } \\
\text { clínico }\end{array}$ & $\begin{array}{c}\text { Diagnóstico } \\
\text { serológico }\end{array}$ & $\begin{array}{c}\text { \% de x } \\
\text { coincidencia }\end{array}$ \\
\hline Rubéola & 72 & 54 & 75,0 \\
Dengue & 63 & 63 & 100,0 \\
CMV & 27 & 4 & 14,8 \\
EBV & 46 & 24 & 52,2 \\
Total & 208 & 145 & 69,7 \\
\hline
\end{tabular}




\section{DisCUSIÓN}

La detección de IgM específica es un criterio diagnóstico adecuado para investigar la etiología de los exantemas agudos debidos a infección vírica ${ }^{6-8}$, toda vez que tales cuadros responden, en su práctica totalidad, a infecciones primarias. Esta estrategia diagnóstica es, también, útil para el diagnóstico etiológico de otros cuadros clínicos que responden a las mismas causas, pero que cursan como síndromes febriles agudos acompañados de otros síntomas (adenopatías, cefalea, artralgias y otros) y sin originar la aparición del exantema. Aplicando esa estrategia para investigar la etiología de 267 casos de uno u otro tipo e incluyendo en la investigación ocho agentes víricos distintos (rubéola, sarampión, dengue 1-4, VEB y CMV), se alcanzó un diagnóstico en $78 \%$ de los casos, lo que supone un excelente rendimiento. Aunque los casos restantes pudiesen reflejar fallos de la metodología de diagnóstico utilizada 0 tratarse, en realidad, de cuadros debidos a causas no infecciosas, lo más probable es que se deban a infecciones por otros agentes no incluidos en la presente investigación. El PVB19 y el HVH6 serían los más probables ${ }^{1}$, si bien no se deben olvidar otros de distinta naturaleza, como las rickettsias y ciertas bacterias convencionales.

Tal como cabía esperar en el medio en que se desarrolló el estudio, los virus dengue aparecen como responsables principales de estos cuadros, independientemente de la edad de los pacientes. Aunque la prevalencia de edad determinada en este estudio es similar a la descrita en la literatura previa $^{10}$. Se conoce que la fiebre, mialgias y artralgias son los síntomas más característicos del dengue clásico, en tanto que el exantema es más infrecuente $\mathrm{y}$, cuando aparece, suele cursar con prurito $^{11}$. Sin embargo, en los 108 casos diagnosticados en esta serie el exantema fue un síntoma más frecuente que las mialgias y las artralgias (56,5\% vs 32,4 y $43,5 \%$ ) y cursó con prurito en sólo dos de los 61 casos que lo presentaron. Esto determinó que sólo $58 \%$ de los casos de dengue encontrados en este estudio (63/108) fuesen etiquetados clínicamente como tales, lo que indica que una parte significativa de los casos de dengue clásico que suceden en nuestro medio pasan desapercibidos para los clínicos. Por consiguiente, el diagnóstico de laboratorio de infección por virus a dengue debería contemplarse siempre que se trate de estudiar la etiología de cualquier cuadro exantemático agudo, aun cuando no medie una sospecha clínica de dengue. Esta es un área endémica, pero en el período estudiado no había ningún incremento de los casos de dengue, por lo que la incidencia determinada no está relacionada a un fenómeno epidemiológico particular.

Podría argumentarse que el descenso relativo de la cobertura de vacunación sucedido en el Estado Zulia en el bienio 1996-97 fuese la causa de que el virus de la rubéola aparezca en esta serie como el segundo agente etiológico en orden global de prevalencia (56 casos, 26,9\% de los positivos). Sin embargo, el análisis de dicha prevalencia en función de la edad de los pacientes viene a contradecir el argumento. De hecho, sólo cuatro de los 56 casos detectados sucedieron en niños menores de diez años; y más de la mitad correspondieron a personas mayores de 20 años, observándose casos incluso en pacientes mayores de 40 años. Estos datos parecen sugerir que el virus continúa circulando abundantemente entre la población estudiada, con intensidad suficiente como para seguir alcanzando el pequeño segmento de población adulta que no sufrió la infección en la infancia. Es, precisamente, esta situación la que permite que continúen produciéndose infecciones agudas en las mujeres gestantes $\mathrm{y}$, por tanto, transmisión vertical del agente y casos de rubéola congénita, que son los que el programa de vacunación pretende evitar.

En consecuencia, cabe recomendar a la Autoridad Sanitaria un mayor esfuerzo en alcanzar coberturas de vacunación elevadas, a objeto que el programa de vacunación en curso llegue a producir los frutos apetecidos.

El exantema estuvo presente en todos los casos y se acompañó, como es habitual, de adenopatías en la mayoría de ellos. A diferencia de lo observado para el virus de la rubéola, la ausencia de casos atribuibles a infección por el virus del sarampión viene a confirmar el éxito de las campañas de vacunación desarrolladas frente a este agente en nuestro medio ${ }^{12}$.

De los dos herpesvirus estudiados, sólo el VEB ha mostrado en la serie una participación relevan- 
te en la etiología de estos cuadros, respondiendo por $19,2 \%$ de los casos positivos. Aun cuando la primoinfección por VEB se haya descrito tradicionalmente como característica de la adolescencia, lo cierto es que, en muchos lugares, es más común en la edad infantil ${ }^{13}$. En la presente serie, casi las dos terceras partes de los casos $(26 / 40$, $65 \%)$ se observaron en menores de 10 años, lo que indica que este último patrón de circulación es el que domina en el Estado Zulia. En esta situación, la mayoría de las infecciones son asintomáticas y los casos típicos de mononucleosis infecciosa son menos frecuentes, toda vez que esta enfermedad se manifiesta con mayor frecuencia a medida que aumenta la edad del individuo que sufre la primoinfección aguda.

Atendiendo a los resultados, el VEB tiende a producir en nuestro medio un cuadro febril acompañado de adenopatías y, en menor medida, de cefalea y exantema, en niños menores de 10 años, aunque no falten tampoco los casos en adolescentes y adultos. Dada la escasa especificidad de esta sintomatología, no sorprende que el diagnóstico clínico de presunción falle con mucha frecuencia, de forma que el diagnóstico correcto sólo puede alcanzarse a través de los

\section{REFERENCIAS}

1. Scott LA, Stone MS. Viral exanthems. Dermatol Online J 2003; 9: 4.

2. Weerasekera DS, Fernanado S, Weerasekera MM. Susceptibility to rubella among pregnant women and the serological evidence of congenital rubella in newborn babies at Colombo south Teaching Hospital. Ceylon Med J 2003; 48: 51-3.

3. Schooley RT. Epstein-Barr virus (infectious mononucleosis). En: Mandell et al, eds.: Principles and practice of infectious diseases, 5a ed, pp. 13641367. Nueva York, 2000.

4. Pinheiro FP, Corber SJ. Global situation of dengue and dengue hemorrhagic fever and its emergence in the Americas. WHO Stat Q 1997; 50: 161-9.

5. Kuno G, Igarashi A. Antibody capture ELISA for detection of immunoglobulin $\mathrm{M}$ antibody in sera estudios de laboratorio. Por lo que respecta al $\mathrm{CMV}$, su escasa detección en esta serie (cuatro casos) no permite extraer ninguna conclusión de interés.

En resumen, los datos que se presentan en este trabajo vienen a demostrar que la participación del laboratorio es esencial para identificar correctamente la etiología de los cuadros exantemáticos y los síndromes febriles agudos que se producen en nuestro medio y que el diagnóstico clínico no es, en sí mismo, suficiente para proporcionar datos fiables acerca de la prevalencia y los patrones de circulación de los agentes víricos que los producen. La investigación de IgM específica en una muestra única de sangre, tomada durante la fase aguda de la enfermedad, permite realizar dicha identificación con un rendimiento muy alto (78\% en este estudio) que, no obstante, podría aún incrementarse incluyendo otros agentes (PVHB19, HVH6) todavía muy poco investigados en nuestro medio. A tenor de lo observado en esta investigación, debería reforzarse la actuación sanitaria en lo que respecta a la vacunación frente a la rubéola si se quiere incidir significativamente sobre la rubéola congénita en el Estado Zulia.

from Japanese encephalitis and dengue haemorrhagic fever patients. J Virol Methods 1985; 11: 1522.

6. Tookey PA, Cortina-Borja M, Peckhman CS. Rubella susceptibility among pregnant women in North London, 1996-1999. J Public Health Med 2002; 24: 211-6.

7. Grotto I, Mimouni D, Huerta M, Mimouni M, Cohen D, RoBIN G ET AL. Clinical and laboratory presentation of EBV positive infectious mononucleosis in young adults. Epidemiol Infect 2003; 131: 683-9.

8. Sсотt LA, Stone MS. Viral exanthems. Dermatol Online J 2003; 9: 4.

9. Dirección General de Eidemiología. Dengue: distribución anual de casos y tasas según municipios, 1990-1998. Boletín Epidemiológico del Estado Zulia № 1. 1999.

10. Oо I EE, Goh KT, CheE Wang DN. Effect of increasing age on the trend of dengue and 
dengue hemorrhagic fever in Singapore. Int J Infect Dis 2003; 7: 231-2.

11. TRILA A, Alonso PL Infecciones causadas por Arbovirus y Arenavirus: viriasis transmitidas por artrópodos y roedores. En: Rozman et al, eds: Medicina Interna Farreras-Rozman, vol. II, 14 ${ }^{\mathrm{a}}$ ed., pp. 2859-2860. Madrid, 2000.
12. Godoy BOA, Betancourt MD, Paublini H, Cadozo RM, OletTa JF, HernándeZ HR et al. Inmunizaciones en Venezuela, 5a Ministerio de Sanidad y Asistencia Social. Caracas, 1998.

13. Schmidt CW, Misko IS. The ecology and pathology of Epstein-Barr virus. Immunol Cell Biol 1995; 73: 489-504.

\section{Agradecimientos}

Agradecemos al personal del Laboratorio Regional de Referencia Virológica. Lic. Ricardo Atencio y Sra. Luz Marina García, MgSc Leticia Porto por su participación en el procesamiento de las muestras para la determinación de anticuerpos contra rubéola, CMV, EBV y Sarampión. A la Sección de Virología del Instituto de Investigaciones Clínicas por el procesamiento de las muestras para la determinación de anticuerpos contra dengue. 